\title{
Gaugerot ve Carteaud'un Konflüan ve Retiküle Papillomatozisi: Azitromisine Yanıt Veren Bir Olgu Sunumu
}

\author{
Confluent And Reticulated Papillomatosis Of Gougerot And Carteaud: A Case Treated With Azithromycin
}

\author{
Aslıhan Yonca Koçak¹, Bengü Nisa Akay², Aylin Okçu Heper³
}

Dum/upınar Üniversitesi Kütahya Evliya Çelebi Eğitim ve Araștırma , Dustanesi, Dermatoloji klinigi

${ }_{3}^{3}$ Ankara Üniversitesi Tıp Fakültesi Tıbbi Patoloji Anabilim Dalı
Gelis tarihi : 03.05.2012 • Kabul tarihi: 02.12.2013

Iletișim

Uzm. Dr. Aslihan Yonca Koçak

GSM: 05058278246

E-posta: aslihanyy@yahoo.com

Dumlupınar Üniversitesi Kütahya Evliya Çelebi Eğitim ve Araștırma Hastanesi, Dermatoloji kliniği

Konflüan ve retiküle papillomatoz ilk olarak Gaugerot ve Carteaud tarafından tanımlanmıştır. Bu nadir görülen hastalık, merkezde birlesme eğilimi gösteren, cevreye doğru retiküler paternde yayılabilen, hiperkeratotik veya verrüköz papül ve plaklarla karakterlidir. Lezyonlar genellikle meme altı veya epigastrik bölgeden başlayarak, sırta, göğüse, karın üst ve alt bölgelerine yayılır. Hastalığın tedavisinde şu ana kadar çsitli antifungal ilaçlar, antibiyotikler, retinoidler, keratolitikler ve kalsipotriol kullanılmıștır. Burada aiztromisin ile başarıyla tedavi edilen bir konflüan ve retiküle papillomatoz olgusu sunulmaktadır.

Anahtar Sözcükler: Azitromisin, Konflüan ve Retiküle Papillomatoz, Antibiyotikler

Confluent and reticulated papillomatosis was originally described by Gaugerot and Carteaud. This rare disorder is characterised by hyperkeratotic or verrucous papules that can increase in size and coalesce to form a reticular pattern peripherally and confluent plaques centrally. Lesions often manifests initially on inframammary or epigastric skin and then extends to the back, chest, upper and lower abdomen. Up to now, various antifungal agents, antibiotics, retinoids, keratolytics and calcipotriol have been used as treatment. $A$ case of confluent and reticulated papillomatosis successfully treated with azithromycin is presented here.

Key Words: Azithromycin, Confluent and Reticulated Papillomatosis, Antibiotics

Konflüan ve retiküler papillomatoz ilk olarak 1927'de Gaugerot ve Carteaud tarafından tanımlanmıştır (1). Bu nadir görülen hastalık, merkezde birleşme eğilimi gösteren, çevreye doğru retiküler paternde yayilan, hiperkeratotik veya verrüköz papül ve plaklarla karakterlidir (1-3). Lezyonlar genellikle meme altı veya epigastrik bölgeden başlayarak, sirta, göğüse, karın üst ve alt bölgelerine yayılır. Tüm yaş gruplarında görülebilmekle birlikte, genellikle puberte sonrasinda ortaya çıkar (1). Hastalığın tedavisinde şu ana kadar çeşitli antifungal ilaçlar, antibiyotikler, retinoidler, keratolitikler ve kalsipotriol kullanılmıştır (1-4). Burada azitromisin ile başarıyla tedavi edilen bir konflüan ve retiküler papillomatoz olgusu sunulmaktadir.

\section{Olgu Sunumu}

On beş yaşında, kadın hasta, boyun, meme arası, epigastrik ve interskapular bölgede, dört aydır devam eden, asemptomatik, hiperkeratotik, kahverengi lezyonlarla başvurdu (Şekil 1A, 1B) . Lezyonları birleşme eğiliminde ve retiküler tarzda dağılım göstermekteydi. Öyküsünden keratolitik ajanlar ile tedavi verildiği ancak fayda görmediği öğrenildi. Rutin laboratuvar tetkikleri normal düzeydeydi. Potasyum hidroksit ile mantar incelemesi ve Wood 1şığ incelemesi negatifti. Lezyonlu yerinden yapilan deri biyopsisinin dermatopatolojik incelemesinde akantoz, hiperkeratoz ve papillomatoz saptandi. Klinik bulgular ve dermatopatolojik incelemesi korele edildiğinde hastaya konflüan ve retiküler papillomatoz tanisı konuldu. Hastaya bir ay süreyle, haftada üç gün, $500 \mathrm{mg} /$ gün azitromisin tedavisi başlandi. Bir ay sonra hastanın lezyonlarının hafif bir pigmentasyon birakarak gerilediğ $i$ gözlendi (Şekil 2A, 2B). Altı ay sonraki kontrollerinde lezyonlarda tekrarlama gözlenmedi 

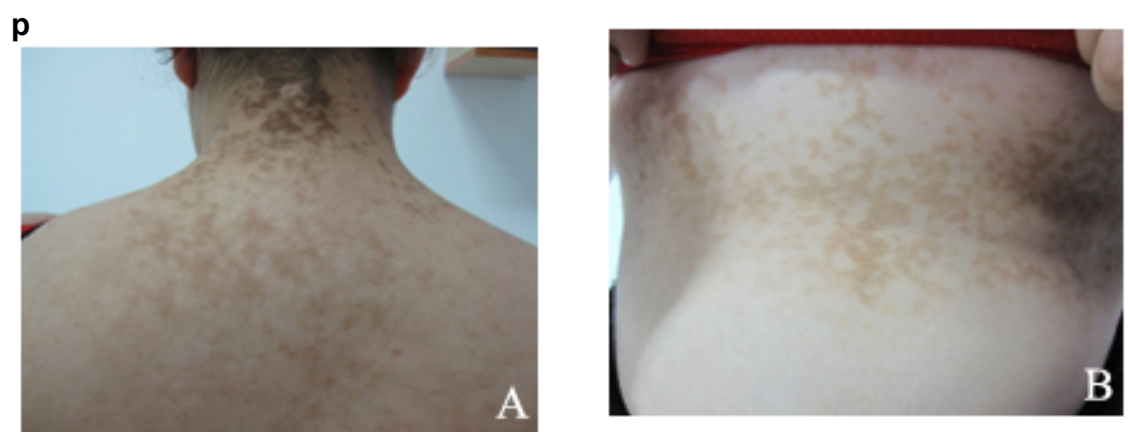

Şekil 1. A. Boyun ve interskapular bölgedeki lezyonların tedavi öncesi görünümü B. Epigastrik bölgedeki lezyonların tedavi öncesi görünümü.
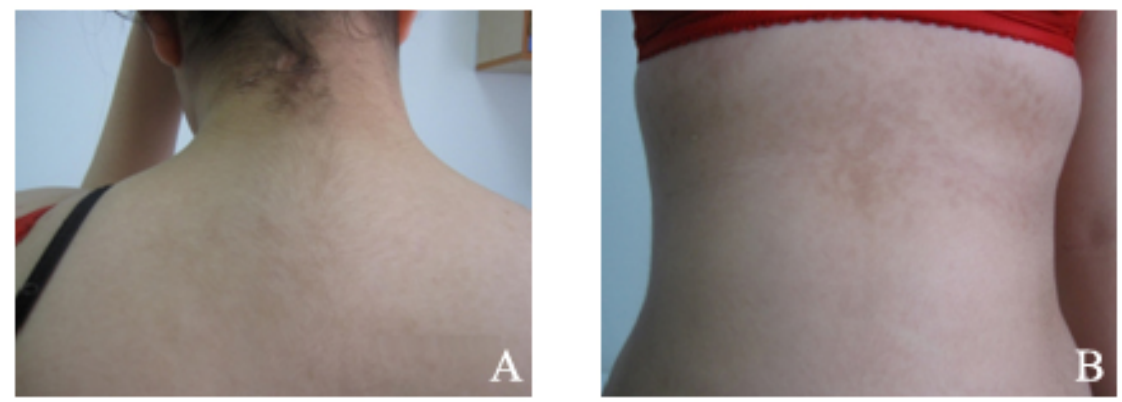

Şekil 2. A. Boyun ve interskapular bölgedeki lezyonların azitromisin tedavisinden üç hafta sonraki görünümü. B: Epigastrik bölgedeki lezyonların azitromisin tedavisinden üç hafta sonraki görünümü.

\section{Tartıșma}

Konflüan ve retiküler papillomatozun etyolojisi ve patogenezi henüz tam olarak aydınlatılamamıştır. En çok üzerinde durulan teoriler, keratinizasyon bozukluğuna genetik yatkınlık, Malessezia türleri ve Dietzia'nın deri üzerinde kolonizasyonuna bağlı anormal konak yanitı veya bakteriyel enfeksiyonlara karşı bir reaksiyon olarak ortaya çıkmasıdır $(1-3,5,6)$. Endokrinopatiler, amiloidoz veya ultraviole ışığı ile de ilişkili olabileceği öne sürülmektedir (1, 3).

Konflüan ve retiküler papillomatoz için standart bir tedavi bulunmamaktadır. Tedaviler geçici olarak başarılı olmakta ancak lezyonlar genellikle tekrar oluşmaktadır (3). İzotretinoin, etretinat, topikal tretinoin ve tazaroten gibi retinoidler, epidermal keratinizas yon ve inflamasyon üzerine etkileri ve immünmodülatuar özellikleri nedeniyle tedavide kullanılmışlardır $\quad(1, \quad 3, \quad 7-10)$. Kalsipotriol, takalsitol, keratolitikler ve selenyum sülfid, ketokonazol gibi çeşitli antifungal ajanlarla tedavi edilen olgular bildirilmiştir (1, 11). Hastalığın oluşumunda bakterilerin rol oynadığı fikrinden yola çıkarak, minosiklin, tetrasiklin, eritromisin, amoksisilin, fusidik asit, klaritromisin, sefdinir, topikal mupirosin, roksitromisin ve azitromisin değişen tedavi yanıtlarıyla kullanılmıştır (1, 2, 4, 12, 13). Antibiyotiklerin, epidermal keratinizasyona neden olan bakterilere karşı, antimikrobiyal etkinin yanısıra, anti-inflamatuvar özellikleriyle ve epitelyal hücrelerin proliferasyonunu engelleyerek etki gösterdiği düşünülmektedir $(2,12)$.

Azitromisin, yan etkisi az, kolay tolere edilebilen ve geniş bir bakteri grubu üzerine etkili makrolid grubu bir antibiyotiktir $(1,8)$. Konflüan ve retiküler papillomatozun tedavisinde etki mekanizması tam olarak anlaş1lamamışır. Makrolidlerin antimikrobiyal aktivitelerinin yanısıra antiinflamatvar etkisi, tümör anjiogenezinin inhibisyonu, vasküler endotelul büyüme faktörü oluşumunun engellenmesi, malign tümör hücrelerinin çoğalmasının in vitro olarak engellenmesi ve keratinosit immünmodülasyonu etkisi vardır (12). Konflüan ve retiküler papillomatoz tedavisindeki etkisinin temelinde antiinflamatuvar

immünmodülatuvar etkilerinin rolü olduğu düşünülmektedir (6, 8). Azitromisinin değişik dozlarda ve sürelerde kullanımı bulunmaktadır. Konflüan ve retiküler papillomatozlu bir olguda, yedi gün süreyle, 500 mg/gün azitromisin kullanıldıktan dört hafta sonra belirgin düzelme izlenmiştir. Hastanın takiplerinde, beş ay sonra az sayıda lezyonun, hafif şiddette tekrarladığ gözlenmiştir (8). Üç hafta süreyle, haftada üç gün, $500 \mathrm{mg} /$ gün kullanilan olgularda, dört hafta sonra lezyonlarda gerileme olduğu bildirilmiştir $(2,3,5,6)$. Bizim olgumuzda da azitromisin, haftada üç kez $500 \mathrm{mg}$ /gün olarak, dört hafta süreyle kullanıldı ve üç hafta sonra lezyonların silindiği gözlendi. Hastanın altı ay sonraki kontrolünde lezyonlarında tekrarlama görülmedi.

Azitromisin, konflüan ve retiküler papillomatoz tedavisinde iyi tolere edilebilmesi ve etkili olması nedeniyle iyi bir tedavi seçeneği olarak görünmektedir. Hastalığın tedavisinde alınan bu iyi yanıt konusunda daha ileri araştırmalara ihtiyaç vardır. 


\section{KAYNAKLAR}

1. Scheinfeld N. Confluent and reticulated papillomatosis: A review of the literature. Am J Clin Dermatol 2006;7:305-13.

2. Jang HS, Oh CK, Cha JH, Cho $\mathrm{SH}$, Kwon KS. Six cases of confluent and reticulated papillomatosis alleviated by various antibiotics. J Am Acad Dermatol 2001;44:652-5.

3. Atasoy M, Ozdemir S, Aktaş A, et al. Treatment of confluent and reticulated papillomatosis with azithromycin. J Dermatol 2004;31:682-6.

4. Gönül M, Cakmak SK, Soylu S, et al. Successful treatment of confluent and reticulated papillomatosis with topical mupirocin. J Eur Acad Dermatol Venereol 2008;22:1140-2.
5. Chaudhry SI, Lai Cheong JE, O'Donoghue NB. A rash on the back. Diagnosis: confluent and reticulated papillomatosis (CRP) of Gougerot and Carteaud. Clin Exp Dermatol 2006;31:727-8.

6. Gruber F, Zamolo G, Saftić M, Peharda V, Kastelan M. Treatment of confluent and reticulated papillomatosis with azithromycin. Clin Exp Dermatol 1998;23:191.

7. Erkek E, Ayva S, Atasoy P, Emeksiz MC. Confluent and reticulated papillomatosis: favourable response to low-dose isotretinoin. J Eur Acad Dermatol Venereol 2009;23:1342-3.

8. Lee MP, Stiller MJ, McClain SA, Shupack JL, Cohen DE. Confluent and reticulated papillomatosis: response to high-dose oral isotretinoin therapy and reassessment of epidemiologic data. J Am Acad Dermatol. 1994;31:32731.
9. Baalbaki SA, Malak JA, al-Khars MA. Confluent and reticulated papillomatosis. Treatment with etretinate. Arch Dermatol 1993;129:961-3.

10. Hodge JA, Ray MC. Confluent and reticulated papillomatosis: response to isotretinoin. J Am Acad Dermatol 1991;24:654.

11. Nordby CA, Mitchell AJ. Confluent and reticulated papillomatosis responsive to selenium sulfide. Int J Dermatol 1986;25:194-9.

12. Ito S, Hatamochi A, Yamazaki S. A case of confluent and reticulated papillomatosis that successfully responded to roxithromycin. J Dermatol 2006;33:71-2.

13. Davis RF, Harman KE. Confluent and reticulated papillomatosis successfully treated with amoxicillin. $\mathrm{Br} J$ Dermatol 2007;156:583-4. 
